\title{
Paper technology
}

Jenna Raunio*, Toni Asikainen, Marko Wilo, Emmi Kallio and Levente Csóka

\section{Affecting the bonding between PLA fibrils and kraft pulp for improving paper dry-strength}

https://doi.org/10.1515/npprj-2019-0033

Received April 8, 2019; accepted November 9, 2019; previously published online January 31, 2020

\begin{abstract}
Polylactic acid fibrils (PLAf) were employed as a fiber component in papermaking. The addition of $5 \mathrm{wt} \%$ of PLAf to bleached kraft birch pulp increased the tensile index of the resulting $100 \mathrm{~g} / \mathrm{m}^{2}$ paper sheets by $20 \%$ in comparison to sheets produced without PLAf. By heattreating the paper sheets containing $5 \mathrm{wt} \%$ PLAf, a $35 \%$ higher tensile index in comparison to sheets produced without PLAf was achieved. SEM imaging showed that the heat-treatment caused the PLAf to melt, which formed a film on the fiber web. The PLAf was ultrasonicated in an attempt to make its surface more hydrophilic and anionic and thus more compatible with cellulose. Chemical additives (cationic polyacrylamide, polyethylene imine and polyethylene glycol) were added to the PLAf/cellulose pulp mixture in order to increase the binding between the ultrasonicated PLAf and cellulose. Ultrasonication caused the PLAf length to decrease and the PLAf surface charge changed by $36 \%$, indicating that the PLAf became significantly more anionic. Neither ultrasonication of PLAf nor the chemical additives improved the paper sheets' stretchability. Polyethyleneimine as an additive in an amount of $1 \%$ increased the tensile index of heat-treated sheets made with $5 \mathrm{wt} \%$ of PLAf by $19 \%$.
\end{abstract}

Keywords: bleached kraft pulp; mechanical properties; papermaking; poly(lactic acid) fibrils; ultrasonication.

\footnotetext{
*Corresponding author: Jenna Raunio, FiberLaboratory, South-Eastern Finland University of Applied Sciences, Vipusenkatu 10, 57200 Savonlinna, Finland, e-mail: jenna.raunio@xamk.fi, ORCID: https://orcid.org/0000-0003-3565-4656

Toni Asikainen, Marko Wilo, Emmi Kallio, FiberLaboratory, South-Eastern Finland University of Applied Sciences, Vipusenkatu 10, 57200 Savonlinna, Finland, e-mails: tontza-89@hotmail.com, marko.wilo@gmail.com,emmi.kallio@xamk.fi Levente Csóka, Institute of Cellulose and Paper Technology, Celltech-Paper Ltd., 9400 Sopron, Hungary, e-mail: csoka.levente@celltech-paper.hu
}

\section{Introduction}

Cellulose and polylactic acid (PLA) are bio-based and biodegradable polymers (Shen et al. 2014). PLA is mostly made from cornstarch via the fermentation of carbohydrates into lactic acid and subsequent polymerization of lactic acid into PLA (Sawada and Ueda 2007). In addition to starch, it is also possible to manufacture PLA from extracts produced in a lignocellulosic biorefinery (Shen et al. 2014). PLA has been widely studied in the context of lignocellulosic materials, and it has many potential applications in this area.

In paper-based packaging applications, PLA can be used to coat paper similarly to polyethylene (Shen et al. 2014). In some composite materials, PLA is used for the matrix and cellulosic fibers are used for reinforcement (Iwatake et al. 2008, Nakagaito et al. 2009). Because PLA is a biodegradable and bio-based plastic whose production can potentially be integrated with cellulose pulping, it is an interesting material to study in the context of papermaking.

A fundamental problem with composite materials comprised of cellulose and PLA is the fact that cellulose pulp fibers have a polar, hydrophilic surface, but PLA has an apolar, hydrophobic surface. These properties cause cellulose and PLA to be poorly compatible (Robles et al. 2018). Some studies have developed methods to overcome this problem by making the cellulose more hydrophobic using an enzymatic treatment (Laadila et al. 2017) or by using chemical compatibilizers such as polyethylene glycol (PEG) (Qu et al. 2010) or polyvinyl alcohol (Yang et al. 2018).

Synthetic fibers, such as PLA and viscose, are already used in non-woven pulp products, such as napkins and filter papers, but are rarely used in wet-laid products. In one study, PLA and viscose fibers were found to increase the tear index of wet-laid papers made from pressure groundwood pulp and chemi-thermomechanical pulp, but as a trade-off, the tensile index and tensile stiffness were reduced (Asikainen and Korpela 2014). In another study, cellulose nanofibrils (CNF) and PLA fibrils (PLAf) were mixed, wet-laid and hot-pressed to produce films. The films' tearing resistance, bursting strength and strain at break all 
decreased with an increasing amount of PLAf, probably due to poor bonding between the PLAf and CNF (Robles et al. 2018). Nakagaito et al. produced composites by mixing microfibrillated cellulose, PLAf and polyacrylamide, followed by wet-laying and hot-pressing the formed material (Nakagaito et al. 2009). As in the Robles et al. study, the mechanical properties decreased with increasing PLAf content. Yang et al. (2018) were able to improve the tensile index, tear index and breaking length of sheets made from PLAf and bamboo pulp fibers by pre-treating the pulp fibers with polyvinyl alcohol, but they did not compare their results to paper made with only pulp fibers. Thus, it remained unclear whether the PLAf was actually a useful paper additive in terms of mechanical properties. Wang et al. (2015) improved the formation of sheets made with PLAf and bamboo pulp by beating the PLAf, but as in the aforementioned studies, the addition of PLAf caused the mechanical properties to degrade.

The compatibility problem of cellulose fibers and PLAf can also be addressed by using foam-forming techniques, which use small aqueous air bubbles as a process fluid instead of water. Pöhler et al. (2017) used foam-forming to make a thermal insulation material from cellulose pulp and PLAf. The PLAf reduced the thermal conductivity, i.e. it improved the material's insulation properties, but the compression strength was also reduced, which was attributed to the reduced number of cellulose-cellulose fiber bonds.

The aim and novelty of this work was to use PLAf as a fiber component in wet-laid papermaking in combination with kraft pulp and compatibilizers with the aim of improving the paper's mechanical properties. The effect of the amount of PLAf, ultrasonication of PLAf and chemical additives on the resulting paper's mechanical properties was studied. The effect of ultrasonication of PLAf on its physical properties and surface charge was also studied. Based on the performed literature survey, PLAf has not been studied as a fiber component in papermaking in this way before. Because cellulose is the main component and PLAf the minor component in this study, the chemical modification of cellulose did not seem reasonable. Instead, modification of PLAf was chosen as the focus. Because PLA is a thermoplastic polymer (Lim et al. 2008) that typically has an ultimate tensile strain of approximately $10 \%$ (Rasal et al. 2010), it was expected that adding PLAf to cellulose pulp could increase the stretch at break of paper.

Ultrasonication of PLAf was hypothesized to cause the PLA polymers on the fibril surface to undergo mechanically induced cleavage, which is known to happen for dissolved polymers (Caruso et al. 2009) and for some electro- spun polymer membranes (Sawawi et al. 2013) subjected to ultrasonication. This cleavage could result in the presence of additional hydroxyl and carboxylic acid groups on the fibril surface, similarly to what happens to PLA under base-catalyzed hydrolysis (Guo et al. 2015). These $\mathrm{OH}$ and $\mathrm{COOH}$ groups would then render the PLAf more hydrophilic and anionic, and thus the PLAf could become more compatible with cellulose.

In addition to PEG, cationic polyacrylamide (C-PAM) and polyethyleneimine (PEI) were chosen as chemical additives for this study, because cationic polymers are known to bind together anionic substances in papermaking (Stenius 2007). Cellulose has an isoelectric point between $\mathrm{pH}$ 2-4, so in neutral pH cellulose should be anionic (Nečesaný 1971). Therefore, if PLAf can be made anionic as well with ultrasonication, C-PAM and PEI might bind the cellulose and PLAf together.

\section{Materials and methods}

\section{Materials}

The PLAf was provided by Tianjin Glory Tang Co., Ltd. (China). Melting point: $160^{\circ} \mathrm{C}$. Melt flow index: $9.7 \mathrm{~g} / 10 \mathrm{~min}$ at $190^{\circ} \mathrm{C}$ for $2.16 \mathrm{~kg}$. Glass transition temperature $58^{\circ} \mathrm{C}$ as determined with DSC at $20^{\circ} \mathrm{C} / \mathrm{min}$ in a $\mathrm{N}_{2}$ atmosphere. The length of the fibrils was $6 \mathrm{~mm}$ and their width was $15 \mu \mathrm{m}$ as determined using Kajaani FS300 fiber analysis equipment. The cellulose pulp was prepared from dry bleached hardwood (Betula pubescens) kraft pulp (BHKP) sheets provided by Stora Enso Imatra, Finland, in a Valley Hollander beater according to Standard ISO 5264-1, and the SR number of the resulting pulp was 25.

C-PAM (Fennopol K 3400P, $7000 \mathrm{~kg} / \mathrm{mol} \mathrm{MW,}$ $1.0 \mathrm{meq} / \mathrm{g}$ charge), PEI (branched, $1.2 \mathrm{~kg} / \mathrm{mol} \mathrm{MW,} 99 \%$ purity) and PEG ( $4 \mathrm{~kg} / \mathrm{mol} \mathrm{MW}$, technical grade purity) were supplied by Kemira Oyj, ThermoFisher and VWR Chemicals, respectively. The chosen C-PAM is a large polyelectrolyte with a low charge density, and the PEI is a small polyelectrolyte with a high charge density. Tap water was used, unless stated otherwise. Poly-DADMAC and PES-Na concentrates were supplied by BTG, and deionized water was used for preparing the titrants.

\section{PLAf ultrasonication}

For the test sheets where ultrasonicated PLAf was used, the ultrasonication was conducted for 20 minutes at a consistency of $0.5 \%$ in a Bransonic MT-5510 ultrasonic bath with a frequency of $42 \mathrm{kHz}$ and power of $185 \mathrm{~W}$. 
The effect of ultrasonication on the physical qualities of the PLAf was studied using Kajaani FS300 fiber analysis equipment. The first sample was simply washed with water. The second sample was prepared in an ultrasonic bath as described above. The third sample was prepared using more intense ultrasonication in a consistency of $1 \%$ for 5 minutes using a Hielscher UIP2000 ultrasonic probe at a frequency of $20 \mathrm{kHz}$ and power of $2000 \mathrm{~W}$. All samples were filtered and then dried at $50^{\circ} \mathrm{C}$ for 1 day.

\section{Surface charge measurements for PLAf and cellulose pulp}

The PLAf surface charges were determined using a Mütek PCD-03 particle charge analyzer coupled with a PCD-T3 titrator. Polyelectrolyte measurement was chosen as the method for this study because it measures only the surface charge (Bhardwaj et al. 2004). First, $0.25 \mathrm{~g}$ of PLAf was mixed with $50 \mathrm{ml}$ of $1 \mathrm{mN}$ poly-DADMAC solution for 1 hour. Then the solids were filtered out with a nylon sieve, and $10 \mathrm{ml}$ of the filtrate was titrated with a $1 \mathrm{mN}$ PES-Na solution until the streaming potential was $0 \mathrm{mV}$. In addition, $10 \mathrm{ml}$ of pure $1 \mathrm{mN}$ poly-DADMAC solution was also titrated with $1 \mathrm{mN}$ PES-Na solution to get a "blank measurement." All steps were made at a pH of approximately 8. All titrations were performed twice, and an average was calculated for the titrant volume.

The fibril surface charges were, based on the study by Bhardwaj et al. (2004), calculated using the following equation $q=\frac{\left(V_{p}-V_{b}\right) * c * 5}{w}$. Here $q$ is the specific fibril surface charge (meq/ $/ \mathrm{kg}), V_{p}$ is the amount of titrant spent on the sample filtrate (l), $V_{b}$ is the amount of titrant spent on the blank measurement (l), $c$ is the concentration of the titrant $(\mathrm{mmol} / \mathrm{l})$, and $w$ is the weight of the dry sample $(\mathrm{kg})$. The equation is multiplied by a factor of 5 to account for the fact that $50 \mathrm{ml}$ of poly-DADMAC was used but only $10 \mathrm{ml}$ of it was titrated in one measurement.

For the surface charge determination of cellulose pulp fibers, the pulp was washed with deionized water before adding the $1 \mathrm{mN}$ poly-DACMAC solution. Otherwise, the procedure was the same as for the PLAf. After the separation of the filtrate, the pulp was dried to determine the dry weight.

\section{Test sheet preparation}

The PLAf was added to the pulp by mixing in a Lorentzen \& Wettre pulp disintegrator for 25,000 rotations. Ultrasonicated PLAf was added as a slurry, and non-sonicated PLAf was added as dry fibril. The ultrasonication of the PLAf used for test sheet preparation was always performed in the ultrasonic bath as detailed previously. The more intensely ultrasonicated (with the ultrasonic probe) PLAf was not used for sheet preparation. The chemical additives were dissolved and diluted in deionized water at $0.05 \%$ (C-PAM) or 1.0 \% (PEI and PEG) consistency, after which they were manually mixed into the pulp for 1 minute after pulp disintegration. The additive amounts in relation to the dry PLAf/cellulose pulp mixture were $0.1 \%$ for C-PAM, $1 \%$ for PEI and 1 and $10 \%$ for PEG. For all test sheets that were made with chemical additives, the used PLAf was modified by ultrasonication because it was expected that the ultrasonication would enable the additive chemicals to react with the PLAf surface.

Paper sheets were made with a sheet mold according to Standard ISO 5269-1. Air mixing was not used, to avoid separation of the PLAf from the pulp. The test sheet grammage was $100 \pm 5 \mathrm{~g} / \mathrm{m}^{2}$. The sheets were allowed to dry for 24 hours at a humidity of $50 \pm 2 \%$ and a temperature of $23 \pm 1{ }^{\circ} \mathrm{C}$. Controlling the moisture of the sheets is important because it is known that PLA can undergo degradation when exposed to heat and moisture (Virtanen et al. 2016).

After drying, heat-treatment was performed on some of the sheets using a Lorentzen \& Wettre Rapid Dryer laboratory grill. The sheets were placed into the grill for $30 \mathrm{sec}-$ onds between two pieces of greaseproof paper to prevent molten PLA from sticking to the grill. The temperature of the grill's surface was measured with an IR thermometer to be approximately $170^{\circ} \mathrm{C}$. Pressure was not applied during the heat-treatment. Afterwards, the sheets were allowed to cool down to room temperature.

\section{Mechanical testing}

The functional properties of the prepared paper sheets - grammage, thickness, tensile index and stretch at break - were measured according to Standards ISO 5270, ISO 536, ISO 534 and ISO 1924-2. The humidity and temperature in the testing area were $50 \pm 2 \%$ and $23 \pm 1{ }^{\circ} \mathrm{C}$. Each measurement point contained two paper strips from each of five sheets (10 strips in total). The measured grammage of the sheets was used for determining the tensile index and bulk. The grammage was roughly unchanged between trial points $\left(100 \pm 5 \mathrm{~g} / \mathrm{m}^{2}\right)$.

\section{Electron microscopy}

A Hitachi S-3400N instrument was used for scanning electron microscopy (SEM) imaging of both the modified and 
Table 1: PLAf length, width and fines content with varying ultrasonication treatment.

\begin{tabular}{|c|c|c|c|c|c|c|c|c|}
\hline \multirow{2}{*}{ PLAf treatment } & \multicolumn{3}{|c|}{ Length (mm) } & \multicolumn{3}{|c|}{ Width $(\mu \mathrm{m})$} & \multicolumn{2}{|c|}{ Fines content (\%) } \\
\hline & $\mathrm{n}$ & $\mathrm{l}$ & $\bar{w}$ & $\mathbf{n}$ & l & $\bar{w}$ & $n$ & \\
\hline Washed only & 4.05 & 5.37 & 5.73 & 15.25 & 14.87 & 14.65 & 4.33 & 0.12 \\
\hline Ultrasonic bath & 3.58 & 5.12 & 5.60 & 16.13 & 14.86 & 14.56 & 5.69 & 0.18 \\
\hline Ultrasonic probe & 2.29 & 4.36 & 5.19 & 15,79 & 15.00 & 14.72 & 13.76 & 0.63 \\
\hline
\end{tabular}

unmodified composite sheets. The images were obtained at an operating voltage of $15 \mathrm{kV}$ in backscattered electron (BSE) mode.

\section{Results and discussion}

\section{Effect of ultrasonication on PLAf}

The main results from the Kajaani FS300 fiber analyses are compiled in Table 1 . The letters $n, l$ and $w$ refer to the fibril length or width averages weighted by the number, length or weight of the fibrils, respectively. Figures 1-3 show the population distributions from the fiber analyses for PLAf.

As seen from Table 1 and Figures 1-3, the PLAf length was reduced and the fines content increased with increasing ultrasonication intensity. In the heavily ultrasonicated PLAf (Figure 3), the fibril length was reduced significantly. The PLAf width, however, was not affected. In this case, fines are fibrils and particles smaller than $0.2 \mathrm{~mm}$ in length. These fiber analysis results show that the ultrasonication affected the physical structure of the PLAf.

The surface charges of the unmodified PLAf (sample A), the PLAf sonicated in the ultrasonic bath for $20 \mathrm{~min}$ (sample B) and the cellulose pulp (sample C, dry weight $0.24 \mathrm{~g}$ ) were determined. The results seen in Table 2 show that the untreated PLAf has quite a small surface charge and that the ultrasonication increased it significantly by $36 \%$ (from -4.4 to $-6.0 \mathrm{meq} / \mathrm{kg}$ ). This can imply that the ultrasonication was successful in increasing the amount of $\mathrm{COOH}$ groups on the PLAf surface. A second explanation for the increased surface charge would be that the broken PLAf simply has a larger surface area, and thus it adsorbs more of the cationic polyelectrolyte. Despite the increase in the PLAf surface charge, it remained far below the surface charge of cellulose pulp $(-41.5 \mathrm{meq} / \mathrm{kg})$. For reference, the study by Bhardwaj et al. (2004) reported that bleached softwood kraft pulp had a surface charge of approximately $30 \mathrm{meq} / \mathrm{kg}$.

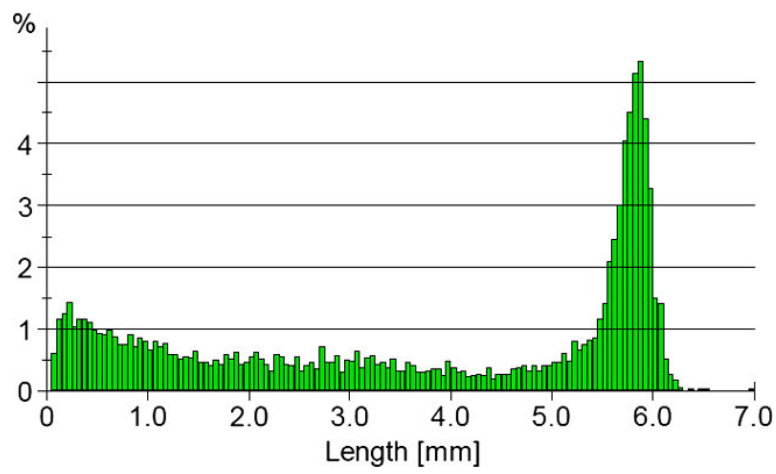

Figure 1: Population distributions of fibril lengths for PLAf washed with water only.

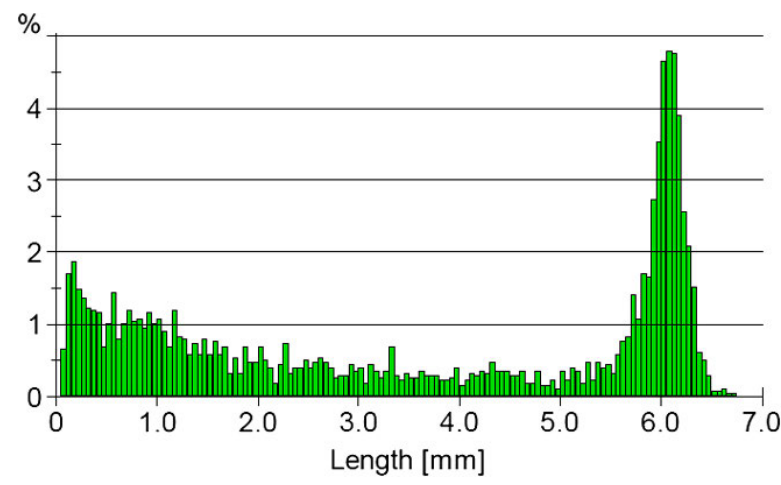

Figure 2: Population distributions of fibril lengths for PLAf mildly sonicated in the ultrasonic bath for $20 \mathrm{~min}$.

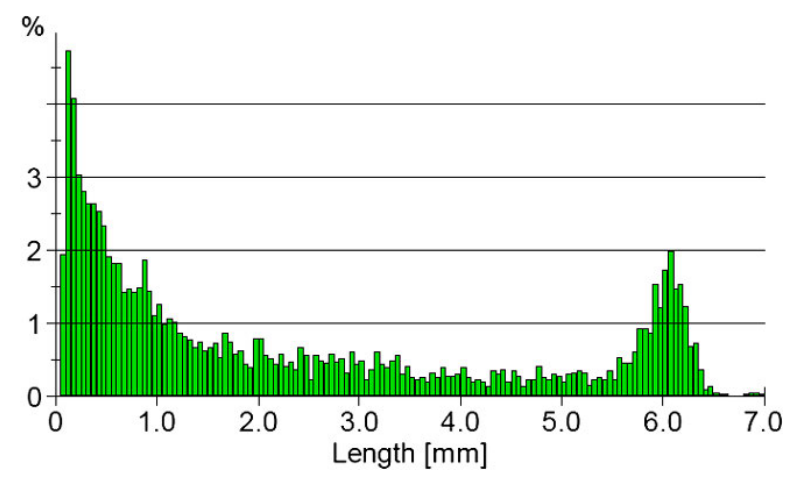

Figure 3: Population distributions of fibril lengths for PLAf heavily sonicated with the ultrasonic probe for $5 \mathrm{~min}$. 
Table 2: PLAf surface charges calculated from the polyelectrolyte titration.

\begin{tabular}{lrr}
\hline & $\begin{array}{r}\text { PES-Na spent on sample } \\
(\mathrm{ml})\end{array}$ & $\begin{array}{r}\text { Fiber surface charge } \\
(\mathrm{meq} / \mathbf{k g})\end{array}$ \\
\hline Blank & 10.56 & - \\
A & 10.34 & -4.4 \\
B & 10.26 & -6.0 \\
C & 8.57 & -41.5 \\
\hline
\end{tabular}

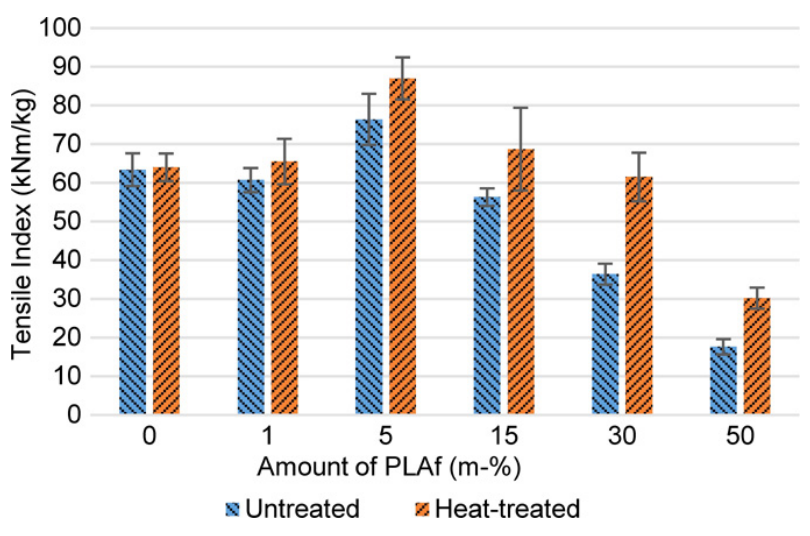

Figure 4: Tensile index of paper sheets made with varying amounts of unmodified PLAf.

\section{Effect of PLAf amount on the mechanical properties of paper}

Figure 4 shows the tensile indices of paper sheets prepared with varying amounts of unmodified PLAf. A PLAf amount of $5 \%$ (in relation to the dry mass of the PLAf/cellulose pulp mixture) gave the highest tensile index. Heat treatment further increased the tensile index. "Untreated" in Figure 4 refers to sheets that had not been subjected to heat-treatment. Higher PLAf amounts than 5\% reduced the tensile index almost linearly. A $5 \%$ amount of PLAf increased the tensile index by $20 \%$ (tensile index increased from 63.4 to $76.4 \mathrm{kNm} / \mathrm{kg}$ ) for untreated sheets and by $35 \%$ (tensile index increased from 64.0 to $87 \mathrm{kNm} / \mathrm{kg}$ ) for heattreated sheets, when compared to sheets made with $0 \%$ PLAf.

The reduction in the tensile index after $5 \%$ is likely due to the PLAf starting to interfere with the cellulosecellulose bonding. A higher amount of PLAf induces electrostatic interaction, which is a much weaker chemical bond than an $\mathrm{OH}$ bond. Moreover, the polar surface of cellulose creates difficulties in uniform dispersion with apolar PLAf plastics. Although PLAf is an apolar synthetic polymer, it contains polar groups like $\mathrm{C}=\mathrm{O}$ as well, which can help the chemical interactions, for example the hydro-

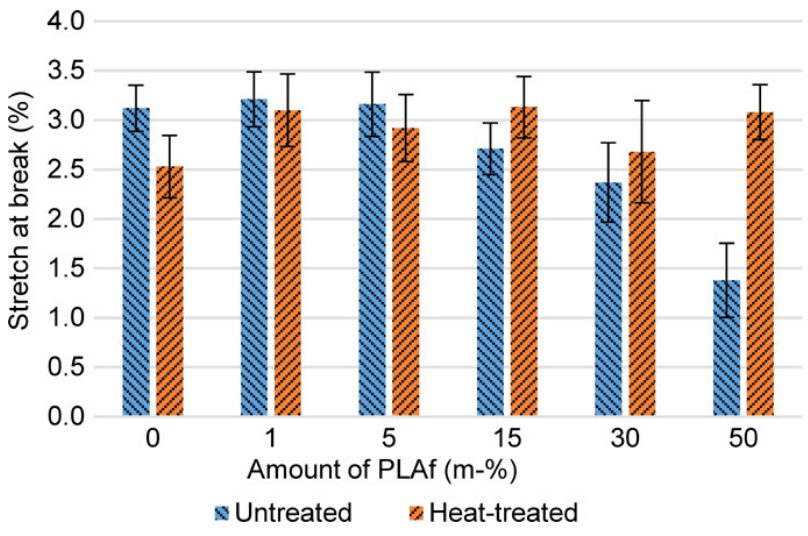

Figure 5: Stretch at break of paper sheets made with varying amounts of unmodified PLAf.

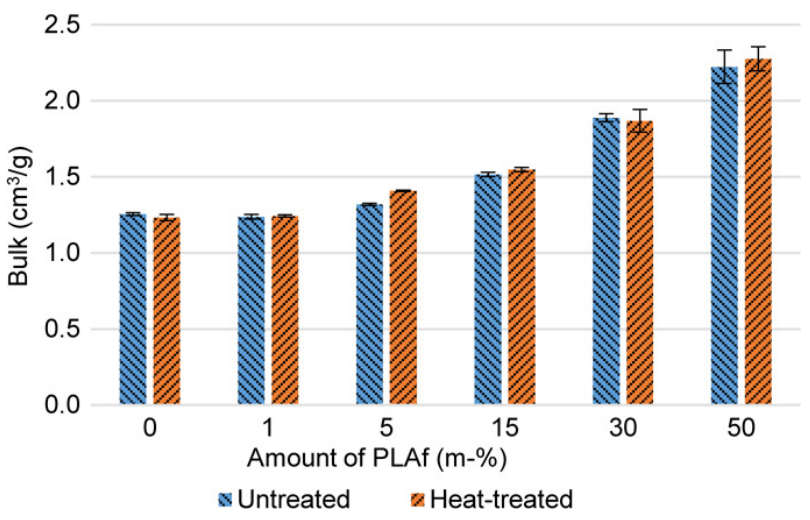

Figure 6: Bulk of paper sheets made with varying amounts of unmodified PLAf.

gen bond formation between cellulose $\mathrm{OH}$ and PLA C $=\mathrm{O}$ groups (Nakayama and Hayashi 2007). Another reason for the reduction in sheet strength, when the PLAf amount was over $5 \%$, is simply the reduced amount of cellulose fibers and the increased amount of more poorly bonding PLAf. On the other hand, cellulose shrinks during drying, which can pull apart the $\mathrm{OH}$ bonds.

Figure 5 shows the stretch at break values for paper sheets prepared with varying amounts of unmodified PLAf. Unlike with the tensile indices in Figure 4, the effect of PLAf on stretch at break is less clear. For untreated sheets, the stretch at break declines quite linearly with increasing PLAf content starting from $15 \mathrm{wt} \%$. For the heattreated sheets, the stretch at break remains rather constant for all PLAf contents. Overall, PLAf as a fiber component did not improve the stretch at break at any test point.

In Figure 6, the values of bulk calculated based on the thickness measurements for the aforementioned test sheets are shown. The bulk clearly increased as the amount of PLAf increased. The PLAf is larger, more rigid 


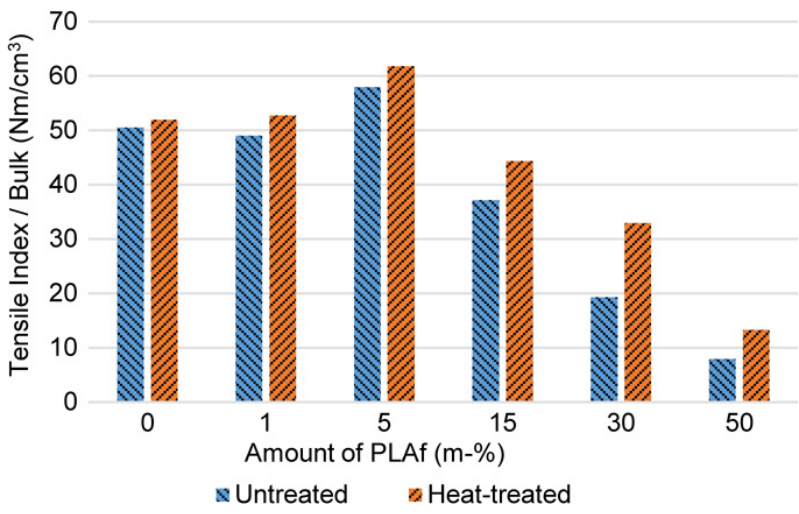

Figure 7: Tensile index of paper sheets made with varying amounts of unmodified PLAf divided by the bulk.

and contains less fines than the cellulose pulp. Thus when the amount of PLAf increases, it seems reasonable that the sheet structure would contain more empty space, which increases bulk.

Figure 7 simply shows the tensile indices (Figure 4) divided by bulk values (Figure 6) for the aforementioned test sheets. Now the sheets containing high amounts PLAf show even a more reduced value than in Figure 4, and $5 \%$ of PLAf still stands out as the optimal amount of PLAf concerning strength.

SEM micrographs taken from sheets prepared with 5 and $30 \mathrm{wt} \%$ PLAf are presented in Figure 8. The PLAf can be easily distinguished from the non-heat-treated sheets as smooth and long fibrils. In the heat-treated sheets, the PLAf has melted. This can be seen particularly well for the sheet containing $30 \%$ PLAf, in which the PLAf has formed a film into the sheet's structure. This likely increases the physical bonding between PLA and cellulose, which could explain the increase in the tensile index seen in Figure 4 for heat-treated sheets.

\section{Effect of PLAf ultrasonication on the mechanical properties of paper}

The effect of ultrasonication on the tensile indices of paper made with $5 \%$ and $15 \%$ PLAf is shown in Figure 9. The ultrasonication causes a reduction in the tensile index
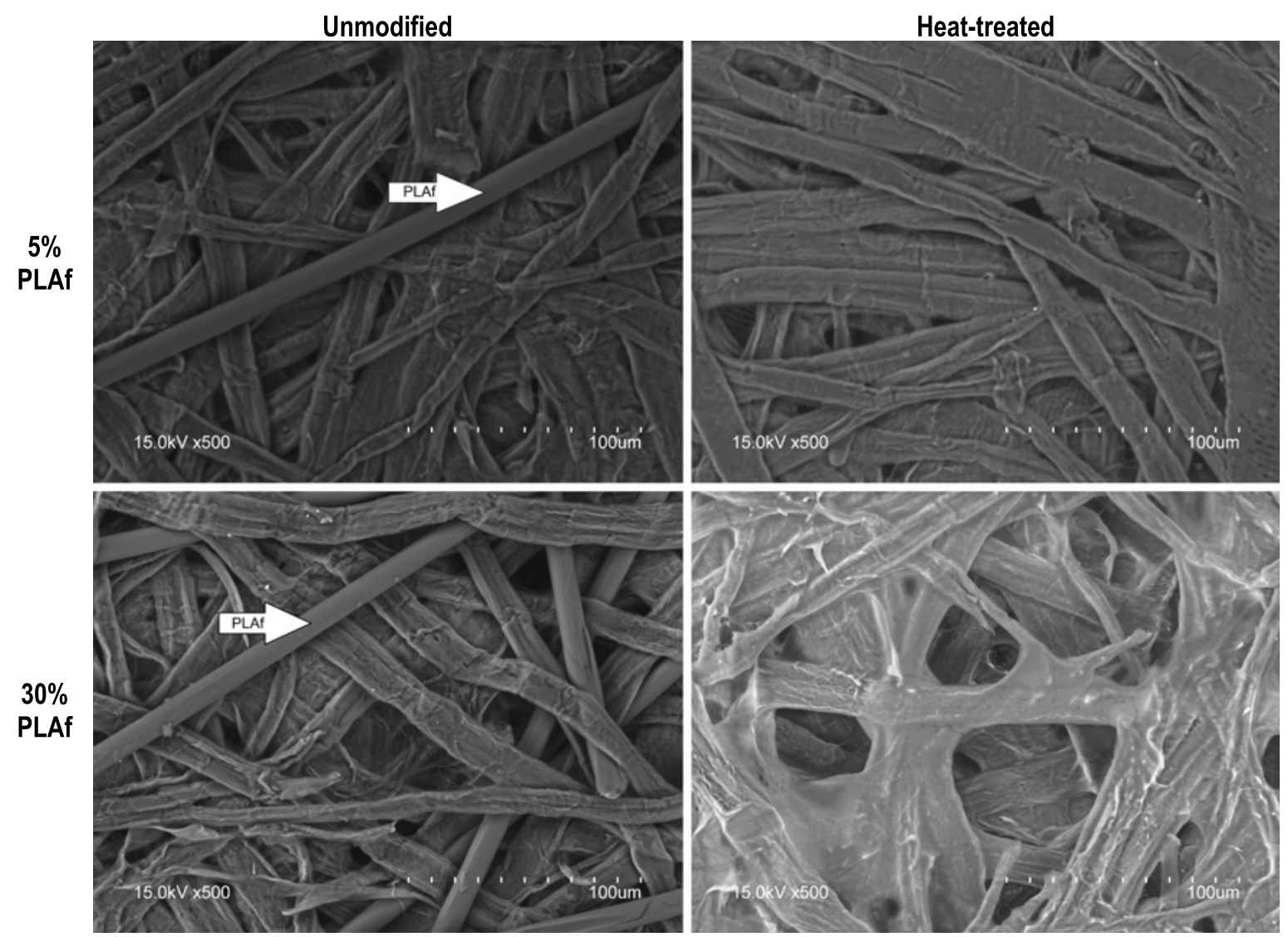

Figure 8: SEM micrographs taken from sheets containing $5 \%$ PLAf (top) and $30 \%$ PLAf (bottom). Micrographs on the left are from unmodified sheets and on the right are from heat-treated sheets. 


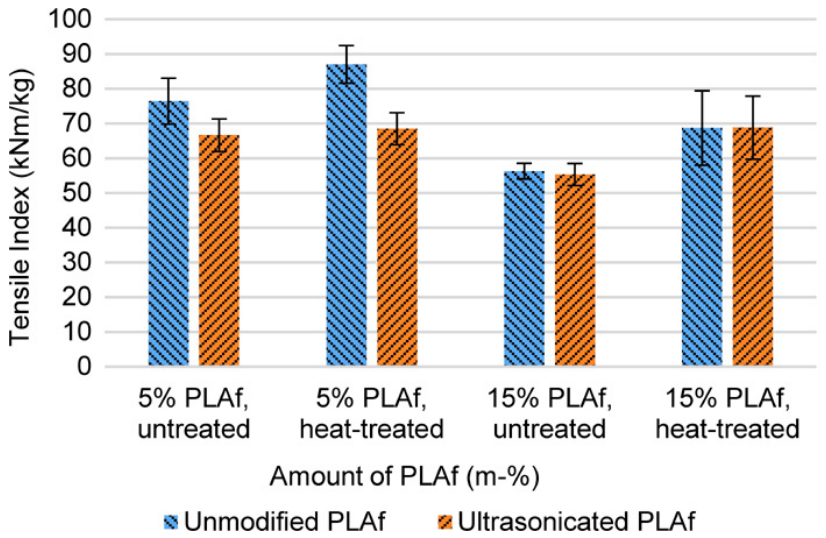

Figure 9: Tensile index of paper sheets made with $5 \%$ and $15 \%$ of non-ultrasonicated and ultrasonicated PLAf.

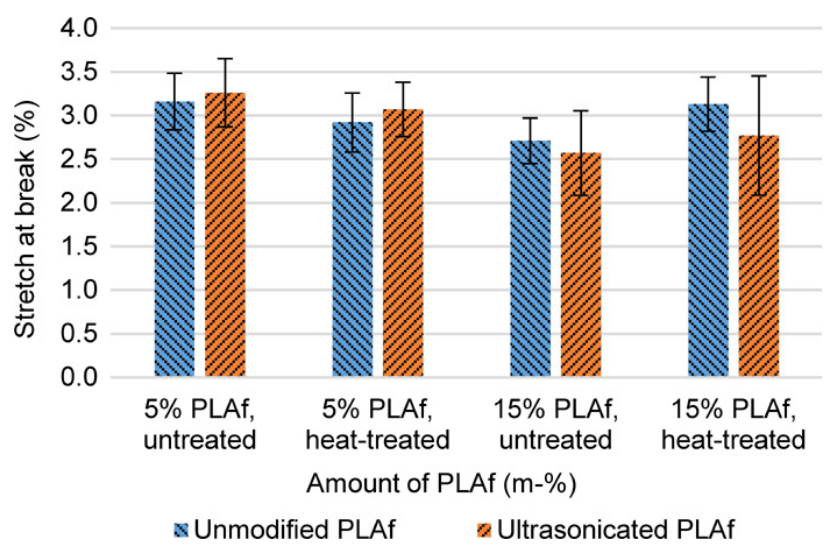

Figure 10: Stretch at break of paper sheets made with $5 \%$ and $15 \%$ of non-ultrasonicated and ultrasonicated PLAf.

of papers made with $5 \%$ PLAf, but sheets made with $15 \%$ PLAf do not experience such a reduction in tensile index. The reduction in tensile index for sheets with $5 \%$ PLAf is surprising, because the hypothesis was that ultrasonication would improve the bonding of the PLAf with cellulose by making the PLAf more hydrophilic. This hypothesis was based on two previous research findings. First, it has been shown that PLA can undergo chain scission when exposed to ultrasonication (Caruso et al. 2009, Sawawi et al. 2013). Second, chain scission of PLA by hydrolysis has been shown to form new $\mathrm{OH}$ and $\mathrm{COOH}$ groups, which increase the PLA surface's hydrophilicity (Guo et al. 2015). It seems, however, that the ultrasonication treatment could not bring the surface charges close to that of the cellulosic fibers. The fiber analysis done for the ultrasonicated PLAf (Figure 2) revealed that ultrasonication had reduced the fibril length by a small amount. Thus, the reduction in the tensile index might partially be explainable by a reduction in the size of the PLAf.

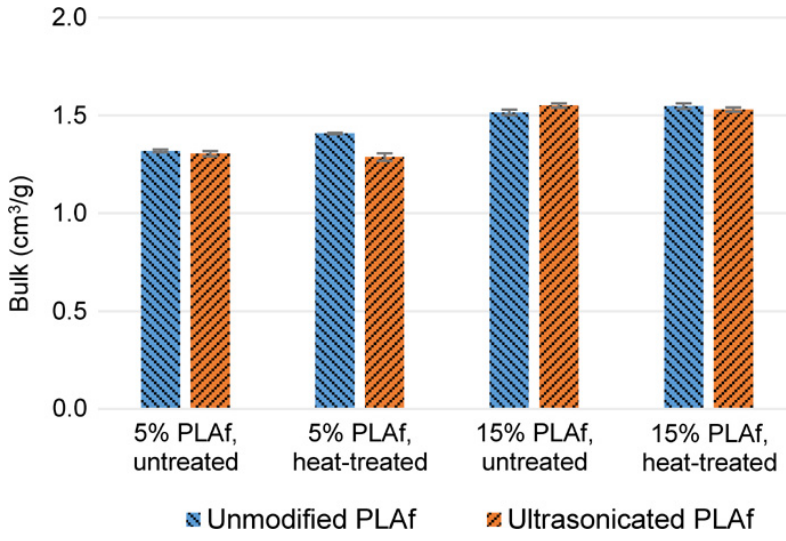

Figure 11: Bulk of paper sheets made with $5 \%$ and $15 \%$ of nonultrasonicated and ultrasonicated PLAf.

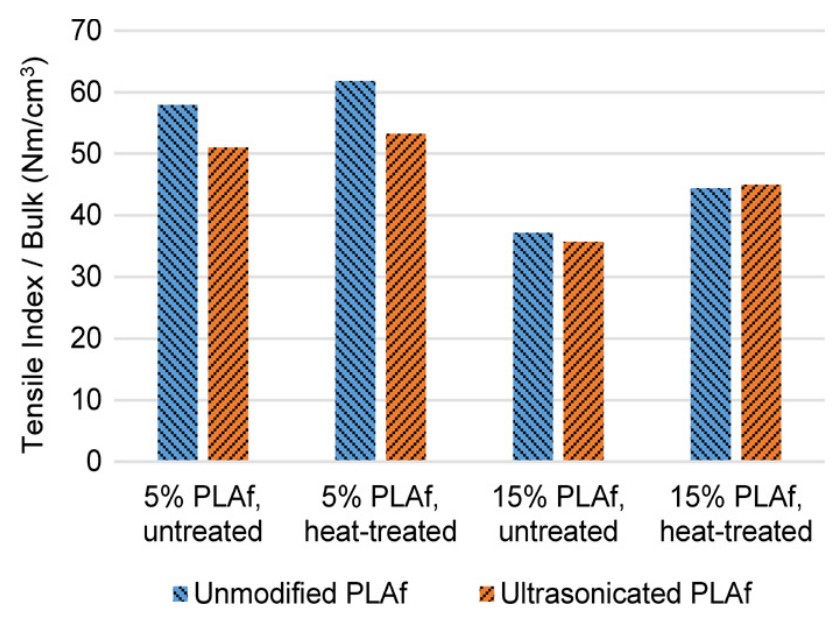

Figure 12: Tensile index of paper sheets made with $5 \%$ and $15 \%$ of non-ultrasonicated and ultrasonicated PLAf divided by the bulk.

The effect of ultrasonication on stretch at break values for paper sheets made with $5 \%$ and $15 \%$ PLAf, as seen in Figure 10, is very small and fits into the standard deviation.

The bulk of the aforementioned sheets is shown in Figure 11, and Figure 12 shows the tensile indices (Figure 9) divided by the bulk values. As the bulk values were quite constant, i.e. the ultrasonication of PLAf did not change the thickness of the sheets, Figures 9 and 12 are almost identical.

\section{Effect of chemical additives on the mechanical properties of paper}

The effect of C-PAM, PEI and PEG on the tensile index and stretch at break of paper sheets made with $0 \%$ and $5 \%$ PLAf were tested. The PLAf was modified using ultrasonication as described above. The additive amounts 


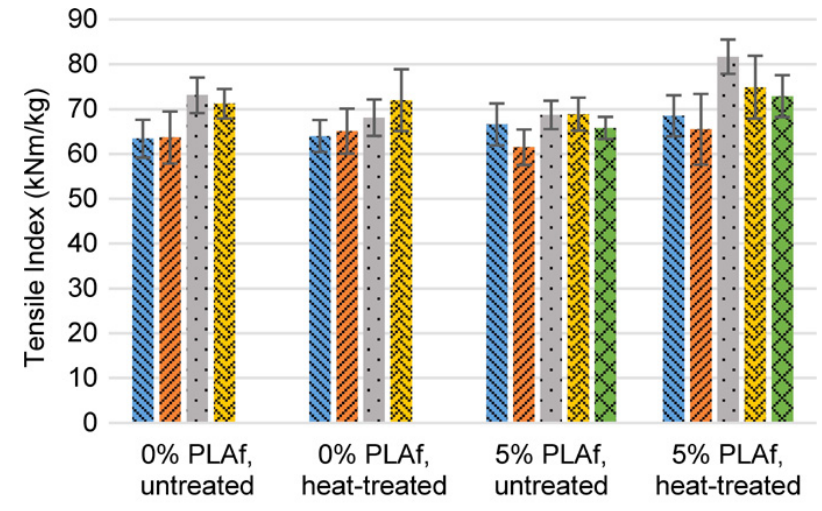

\& No additive \&C-PAM $0.1 \%$ \&PEI $1 \%$ \&PEG $1 \%$ \&PEG $10 \%$

Figure 13: Tensile index of paper sheets made with $0 \%$ and $5 \%$ ultrasonicated PLAf and chemical additives.

are expressed in relation to the dry mass of the PLAf/cellulose pulp mixture. As can be seen from Figure 13, the chemical additives did not have much effect on the untreated sheets containing $5 \%$ of PLAf. On the other hand, for the heat-treated sheets containing 5\% PLAf, adding $1 \%$ of PEI increased the tensile index by approximately $19 \%$ (from $68.5 \mathrm{kNm} / \mathrm{kg}$ to $81.7 \mathrm{kNm} / \mathrm{kg}$ ), which is a significant improvement. PEG also increased the tensile index of heat-treated sheets with 5\% PLAf slightly when added in amounts of $1 \%$ or $10 \%$.

It was surprising that C-PAM had such a small, or sometimes even negative, effect on strength, because it is often used to increase dry-strength (Stenius 2007). If one compares the molecular weights (MW) and the charge densities of the cationic chemical additives, it seems that a lower MW and a higher charge density is favorable for increasing the dry-strength. The amount of C-PAM was chosen to be $0.1 \%$ because it is in the range of typical C-PAM dosages used in papermaking (Neimo 1999). The amount of PEI was chosen to be $1 \%$ because it is a smaller molecule than C-PAM, and it was thus expected that its dosage should be clearly higher than that of C-PAM so that the PEI would affect the mechanical properties. The amount of PEG was the most difficult to choose because the study by Qu et al., in which they studied the effect of CNF and PEG on PLA, had PLA as the major component where as in this study cellulose is the major component ( $\mathrm{Qu}$ et al. 2010). The amount of PEG was chosen to be 1 and $10 \%$ because $1 \%$ is a reasonable and typical additive chemical amount for papermaking, and $10 \%$ was chosen out of curiosity to observe what would happen with a much larger dose. The reason why PEG improved the tensile index of heat-treated sheets with 5\% PLAf could be that PEG acts as a plasticizer, which penetrates between the cellulose

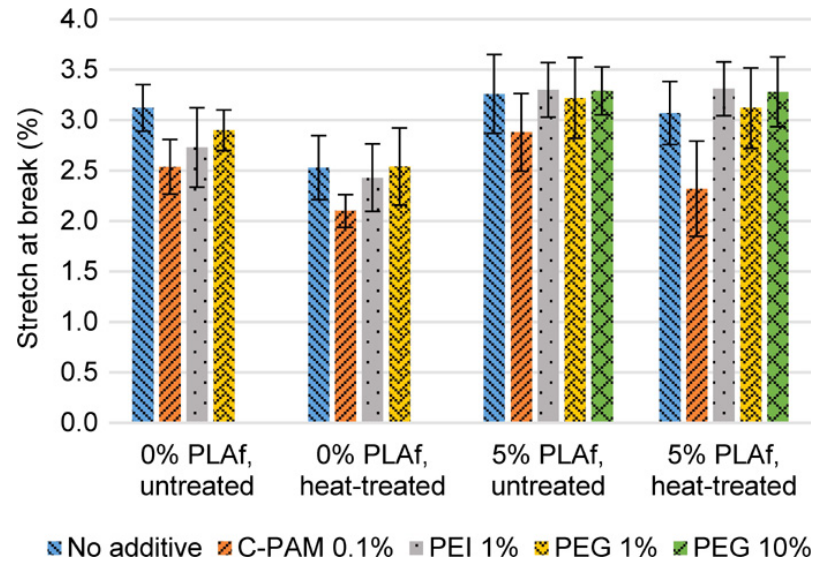

Figure 14: Stretch at break values for paper sheets made with $0 \%$ and $5 \%$ ultrasonicated PLAf and chemical additives.

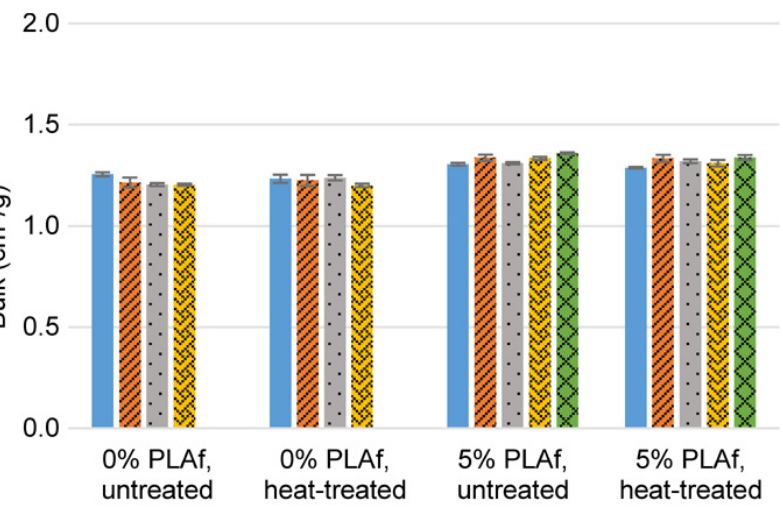

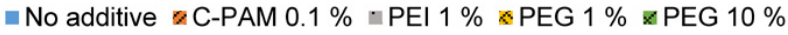

Figure 15: Bulk of paper sheets made with $0 \%$ and $5 \%$ ultrasonicated PLAf and chemical additives.

fibers and PLAf under heat treatment. This may result in improved mechanical properties.

As can be seen from Figure 14, none of the chemical additives improved the stretch at break, and C-PAM even significantly reduced it, especially for heat-treated sheets with $5 \%$ PLAf.

The bulk of the aforementioned sheets is shown in Figure 15, and Figure 16 shows the tensile indices (Figure 13) divided by the bulk values. As the bulk values were quite constant, i. e. the chemical additives did not have an effect on the thickness of the sheets, Figures 13 and 16 are almost identical.

\section{Conclusions}

In this study, it was demonstrated that by adding $5 \mathrm{wt} \%$ of polylactic acid fibrils to bleached kraft birch pulp, the 


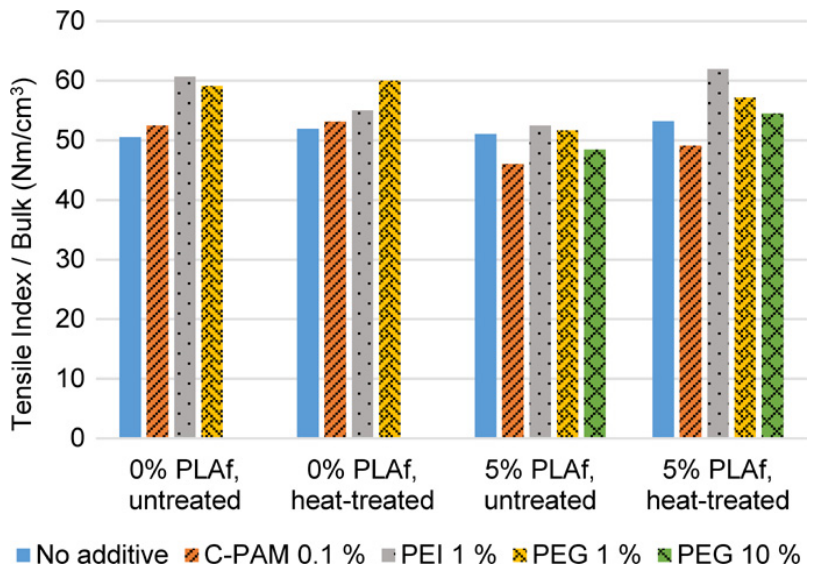

Figure 16: Tensile Index of paper sheets made with $0 \%$ and $5 \%$ ultrasonicated PLAf and chemical additives divided by the bulk.

resulting paper's tensile index could be increased by up to $35 \%$ when compared to sheets made with only cellulose pulp. This is the first time that PLAf has been used as a fiber component in kraft pulp. Using PLAf as a fiber component did not increase the stretch at break of paper in any situation. Heat-treatment of the sheets containing $5 \%$ PLAf significantly increased the tensile index but also slightly reduced the stretch at break.

Ultrasonication of the PLAf and the attempted application of C-PAM, PEI and PEG as binders between cellulose and PLAf proved to be ineffective for increasing stretch at break, and in some cases, the ultrasonication and chemical additives even caused stretch at break to decline. In the case of dry-strength, adding $1 \%$ of polyethyleneimine increased the tensile index of heat-treated sheets made with $5 \%$ of ultrasonicated PLAf by approximately $19 \%$. Other chemical additives did not have a significant effect on the dry-strength.

Based on the fiber surface charge and fiber analysis measurements, ultrasonication had an effect on the physical structure of the PLAf by shortening the fibrils, and a significant effect on the PLAf surface anionicity by $36 \%$, but still not comparable to cellulose fibers' surface charge. To the best of our knowledge, this is the first time that the effect of ultrasonication on PLAf has been studied in this detail. Because the PLAf surface was less anionic than the cellulose fiber surface, the lower MW cationic additive (PEI) probably adhered to the cellulose and not to the PLAf. The reason why the combination of PEI with $5 \mathrm{wt} \%$ of ultrasonicated PLAf gave a higher drystrength than PEI alone might be that the PEI binds the cellulose molecules together, and simultaneously the PLAf works as a physical reinforcement within the cellulose fiber web.
Based on these results, PLAf is a promising fiber component for improving the dry-strength of wet-laid paper. In future studies, it would be good to explore more techniques for modifying the PLAf surface and to examine the properties of the resulting PLAf/cellulose materials. A better understanding of the PLA/cellulose interface in general, and what kind of chemicals could be used to improve PLA/cellulose bonding, would be important for developing new applications. Such research could also have benefits for composite materials where PLA is the matrix and cellulosic fibers are the reinforcement.

Funding: This research was funded as part of a larger research project (NewPro - New high reactivity in-line process knowhow for the Finnish fiberproduct business ecosystem) by the Finnish Funding Agency for Innovation (TEKES), the European Regional Development Fund (ERDF) and partner companies (Project Number A72022). The partner companies were Andritz Oy, Degrémont Technologies AG, Janesko Oy, Ket-Met Oy, Stora Enso Oyj and Wetend Technologies Oy. The funding sources were not involved in the study design or in the collection, interpretation or analysis of the data.

Conflict of interest: The authors declare no conflicts of interest.

\section{References}

Asikainen, J., Korpela, A. (2014) Tear and tensile strength development of PGW and CTMP pulps mixed with PLA or viscose fibres. Nord. Pulp Pap. Res. J. 29(2):304-308.

Bhardwaj, N.K., Duong, T.D., Nguyen, K.L. (2004) Pulp charge determination by different methods: Effect of beating/refining. Colloids Surf. A, Physicochem. Eng. Asp. 236(1):39-44. doi:10.1016/j.colsurfa.2004.01.024.

Caruso, M.M., Davis, D.A., Shen, Q., Odom, S.A., Sottos, N.R., White, S.R., Moore, J.S. (2009) Mechanically-induced chemical changes in polymeric materials. Chem. Rev. 109(11):5755-5798. doi:10.1021/cr9001353.

Guo, C., Xiang, M., Dong, Y. (2015) Surface modification of poly (lactic acid) with an improved alkali-acid hydrolysis method. Mater. Lett. 140:144-147. doi:10.1016/j.matlet.2014.10.099.

Iwatake, A., Nogi, M., Yano, H. (2008) Cellulose nanofiber-reinforced polylactic acid. Compos. Sci. Technol. 68(9):2103-2106. doi:10.1016/j.compscitech.2008.03.006.

Laadila, M.A., Hegde, K., Rouissi, T., Brar, S.K., Galvez, R., Sorelli, L., Cheikh, R.B., Paiva, M., Abokitse, K. (2017) Green synthesis of novel biocomposites from treated cellulosic fibers and recycled bio-plastic polylactic acid. J. Clean. Prod. 164:575-586. doi:10.1016/j.jclepro.2017.06.235.

Lim, L., Auras, R., Rubino, M. (2008) Processing technologies for poly(lactic acid). Prog. Polym. Sci. 33(8):820-852. doi:10.1016/j.progpolymsci.2008.05.004. 
Nakagaito, A.N., Fujimura, A., Sakai, T., Hama, Y., Yano, H. (2009) Production of microfibrillated cellulose (MFC)-reinforced polylactic acid (PLA) nanocomposites from sheets obtained by a papermaking-like process. Compos. Sci. Technol. 69(7):1293-1297. doi:10.1016/j.compscitech.2009.03.004.

Nakayama, N., Hayashi, T. (2007) Preparation and characterization of poly(l-lactic acid)/TiO2 nanoparticle nanocomposite films with high transparency and efficient photodegradability. Polym. Degrad. Stab. 92(7):1255-1264. doi:10.1016/j.polymdegradstab.2007.03.026.

Neimo, L. Papermaking science and technology, book 4: Papermaking chemistry. 1st ed. Fapet Oy, Finland, 1999.

Nečesaný, V. (1971) The isoelectric point of lignified cell walls. Holz Roh-Werkst. 29(9):354-357. doi:10.1007/BF02621436.

Pöhler, T., Jetsu, P., Fougerón, A., Barraud, V. (2017) Use of papermaking pulps in foam-formed thermal insulation materials. Nord. Pulp Pap. Res. J. 32(3):367-374. doi:10.3183/npprj-2017-32-03-p367-374.

Qu, P., Gao, Y., Wu, G., Zhang, L. (2010) Nanocomposites of poly(lactic acid) reinforced with cellulose nanofibrils. BioResources 5:3.

Rasal, R.M., Janorkar, A.V., Hirt, D.E. (2010) Poly(lactic acid) modifications. Prog. Polym. Sci. 35(3):338-356. doi:10.1016/j.progpolymsci.2009.12.003.

Robles, E., Kánnár, A., Labidi, J., Csóka, L. (2018) Assessment of physical properties of self-bonded composites made of cellulose nanofibrils and poly(lactic acid) microfibrils. Cellulose 25(6):3393-3405. doi:10.1007/s10570-018-1822-3.

Sawada, K., Ueda, M. (2007) Optimization of dyeing poly(lactic acid) fibers with vat dyes. Dyes Pigments 74(1):81-84. doi:10.1016/j.dyepig.2006.01.

Sawawi, M., Wang, T.Y., Nisbet, D.R., Simon, G.P. (2013) Scission of electrospun polymer fibres by ultrasonication. Polymer 54(16):4237-4252. doi:10.1016/j.polymer.2013.05.060.

Shen, J., Fatehi, P., Ni, Y. (2014) Biopolymers for surface engineering of paper-based products. Cellulose 21(5):3145-3160. doi:10.1007/s10570-014-0380-6.

Stenius, P. Papermaking science and technology, book 4: Papermaking chemistry 2nd ed. Paperi ja Puu Oy, Finland. 2007.

Virtanen, S., Wikström, L., Immonen, K., Anttila, U., Retulainen, E. (2016) Cellulose kraft pulp reinforced polylactic acid (PLA) composites: effect of fibre moisture content. AIMS Mat. Sci. 3(3):756-769. doi:10.3934/matersci.2016.3.756.

Wang, R., Yang, R., Yang, F. (2015) Production of bamboo fiber reinforced fibrillated poly(lactic acid) (PLA) material obtained by a papermaking process. J. Wuhan Univ. Technol.-Mat. Sci. Ed. 30(2):429-432. doi:10.1007/s11595-015-1165-y.

Yang, F., Ma, H., Tang, L., Feng, Y. (2018) Effect of polyvinyl alcohol treatment on mechanical properties of bamboo/polylactic acid composites. BioResources 13(2):2578-2591. 